\title{
Financiamento da inovação no Brasil: uma abordagem sobre a influência dos incentivos fiscais na atividade inovativa industrial
}

\author{
Innovation financing in Brazil: an approach about the influence of fiscal incentives on \\ industrial innovation activity
}

\author{
Patrine Soares Santos', Maria Thereza Santos Rocha", Sara Gonçalves Antunes de Souza'II
}

\begin{abstract}
Resumo
A atividade inovativa e as etapas que a antecedem, exigem um grande aporte de recursos e contam com uma característica de incerteza sobre o seu retorno, logo o financiamento destas atividades torna-se um entrave ao seu progresso, pois nem sempre os países possuem um sistema financeiro consolidado que propicie as ferramentas de crédito necessárias. Deste modo, o Estado assume função primordial no estímulo à inovação pelo setor produtivo, através de diversos instrumentos de financiamento, sendo os incentivos fiscais os mais utilizados pelos países em desenvolvimento. Neste sentido, o objetivo deste artigo é discutir, sob a perspectiva do financiamento da inovação, a influência dos incentivos fiscais na atividade inovativa industrial, com ênfase nas Leis da Informática e Lei do Bem, com base na literatura concernente ao tema, estudos correlatos e dados secundários sobre os impactos desses mecanismos legais. Conclui-se que estes instrumentos fiscais têm sido importantes para o incremento da atividade inovativa industrial no país, entretanto, tem se concentrado em empresas e setores aos quais estas já eram inerentes ao processo produtivo, além de que, através dos dados analisados, observou-se a ampla participação do autofinanciamento como propulsor do investimento em inovação, indicando a imprescindibilidade de adaptações na legislação.
\end{abstract}

Palavras-Chaves: Financiamento; Inovação; Incentivos Fiscais

\begin{abstract}
The innovative activity and the stages that precede it, require a large amount of resources and have a characteristic of uncertainty about their return, so the financing of these activities becomes a barrier to their progress, since not always the countries have a consolidated financial system that provides the necessary credit tools. Thus, the State assumes a primary function in stimulating innovation by the productive sector through various instruments beeing the fiscal incentives most used by developing countries. In this sense, the objective of this article is to discuss, under the perspective of innovation financing, the influence of fiscal incentives in the industrial innovative activity, with emphasis on Informatics Law and Good Law, based on the literature concerning the subject, related studies and secondary data about the impacts of these legal mechanisms. It is concluded that these fiscal instruments have been important for the increase of the industrial innovation activity in the country, however, it has been concentrated in companies and sectors which they were already inherent to the productive process, besides, through the analyzed data, it was observed the large participation of self-financing as propellant of investment in innovation, indicating the indispensability of adaptations in the legislation.
\end{abstract}

Keywords: Financing; Innovation; Fiscal Incentives

\footnotetext{
Universidade Estadual de Montes Claros - patrineeco15@gmail.com

II Universidade Estadual de Montes Claros - rocha.mariathereza@gmail.com

III Universidade Estadual de Montes Claros - saraunimontes@gmail.com
} 


\section{Introdução}

A abordagem Schumpeteriana coloca em lugar de destaque a inovação e a difusão desta como fator determinante no processo de desenvolvimento econômico e refere-se à empresa como a peça central na criação e propagação da inovação. Nessa perspectiva, a inovação ao introduzir novos processos e produtos na economia, promovendo uma ruptura tecnológica, é decisiva para promoção do desenvolvimento. Diante dessa realidade, diversos países têm buscado desenvolver um Sistema Nacional de Inovação (SNI) a fim de alavancar o seu potencial inovativo, tido como determinante de competitividade no cenário mundial. Para tanto, faz-se necessário consolidar um sistema financeiro eficaz, uma vez que o crédito é posto por Schumpeter $(1911)^{1}$ como um componente monetário da inovação, sendo sua principal fonte de financiamento.

As atividades econômicas têm por característica certo nível de incerteza envolvido no que tange aos seus resultados e a capacidade de retorno do capital investido. Conforme Pavitt (1990), as empresas na busca de lucros são avessas ao risco ou têm horizontes de curto prazo em suas decisões de alocar recursos. Neste contexto, a atividade inovativa encontra restrições de financiamento por se tratar de uma atividade com elevado nível de incerteza sobre o seu retorno. Muitos países, em especial aqueles em desenvolvimento, por apresentarem um sistema financeiro em estado de maturação e ainda, pela característica de risco do processo inovativo, principalmente em sua fase inicial (que inibe a participação do setor bancário na concessão de crédito), têm buscado alternativas para estimular tais atividades.

Diante disso, o papel do estado torna-se crucial no estímulo à inovação pelo setor produtivo através de políticas implícitas como as políticas fiscal, cambial e monetária, que interferem indiretamente no processo de inovação e também das políticas explícitas, que promovem diretamente os investimentos no processo inovativo, como os incentivos fiscais, as subvenções econômicas e os programas de concessão de crédito que compatibilizam o custo do capital investido com o nível de risco dos projetos de inovação, apoiando o setor empresarial e as Instituições de Ciência e Tecnologia (ICT’s). Garcia (2008) ${ }^{2}$ ressalta que gerar conhecimento tecnológico, bem como transformá-lo em riqueza, decorre substancialmente do apoio direto ou indireto do Estado, sendo essencial uma política intensiva de incentivos fiscais para que as empresas invistam nesta direção.

Neste sentido, o presente artigo objetiva abordar, sob a perspectiva do financiamento da inovação, a influência dos incentivos fiscais na atividade inovativa industrial, com ênfase nas Leis da Informática e Lei do Bem. Para atingir o objetivo proposto, com base na literatura concernente ao tema, foi estruturado um referencial teórico bem como o levantamento de estudos correlatos e dados secundários. Subsequente a esta introdução, o trabalho apresenta as seções: i) A importância da Inovação e suas formas de financiamento; ii) Abordagem histórica das políticas de inovação no Brasil; iii) O desempenho das políticas de incentivos fiscais como indutores da atividade inovativa industrial brasileira; iv) Autofinanciamento e, por fim, as considerações finais.

\section{A importância da inovação e suas formas de financiamento}

Escrito em 1911 por Joseph Alois Schumpeter, o livro intitulado “Teoria do Desenvolvimento Econômico" trouxe nova abordagem quanto aos instrumentos determinantes neste processo. Focalizando no papel da inovação como variável fundamental em sua explicação, este autor rompe com a ideia do estado estacionário - situação em que a economia sempre converge para o equilíbrio diante das forças de oferta e demanda do mercado. De acordo com Torres (2012), Schumpeter procurou apontar dentro do capitalismo uma força intrínseca a este sistema, causadora de suas instabilidades. Assim, as mudanças econômicas decorrem daquilo que o autor denomina 'novas combinações', ou ainda, a inovação. Dentro deste conceito engloba-se a introdução: de um novo bem, de um novo método de produção, a abertura de um novo mercado, novas fontes de matéria-prima e ainda, a instauração de nova forma organizacional na indústria (SCHUMPETER, 1911) ${ }^{3}$. Assim, atenta-se à ideia dos ciclos de negócios, ou seja, a introdução de um novo produto ou de um novo processo de produção proporciona a descontinuidade do estado estacionário.

Paula (2011), retrata que ao incorporar a inovação, abrem-se novas perspectivas de lucro e isto desencadeia em diversas mudanças comportamentais dos agentes econômicos. Ao apresentar a ideia de "destruição criadora", Schumpeter afirma que a inovação ocasiona intercadência nos produtos ou nos métodos de produção. Logo, a criação e a introdução de uma nova tecnologia levam ao desaparecimento gradual e na futura extinção das antigas tecnologias.

O responsável por tais inovações, segundo o autor, seria o Empresário. Afirmou que “...alguém só é um empresário quando efetivamente "levar a cabo novas combinações” Schumpeter [1911 (1985, p.86)]. Esse agente inovador e crucial para o entendimento de desenvolvimento para o autor, distingue-se do capitalista, apesar de também visar

1 SCHUMPETER $[(1911,1985)]$

2 Apud PEREIRA (2013)

3 Idem nota 2 
a obtenção de lucros, mesmo que temporários.

A oportunidade de auferir lucros através do monopólio transitório que a empresa possui enquanto pioneira na difusão da inovação, a permite diferenciar-se daquelas que se enquadram como suas concorrentes. A dinâmica econômica causada pela empresa inovativa está no fato de que a empresa precursora consegue obter lucros maiores que o normal, com a introdução e difusão das novas tecnologias, que serão copiadas pelas demais empresas, visando receber os mesmos ganhos que as primeiras, ocorrendo então a transformação dos mercados e dos sistemas produtivos (VALLIM, 2014).

Visando aprofundar as importantes contribuições de Schumpeter, de modo a consolidar o arcabouço teórico sobre a geração e difusão da inovação, estudos foram e estão sendo realizados ancorados nos pilares do progresso técnico e das determinantes da tecnologia como elementos chaves no processo de desenvolvimento econômico. Costa (2016), aponta que a teoria neoschumpeteriana concorda em vários aspectos com a visão de Schumpeter, reforçando a empresa como o agente que promove a inovação, uma vez que inseridas em um ambiente econômico instável e sendo particular as percepções de lucro por cada uma, o que predomina é a diferenciação entre elas, pois estas percebem que a inovação se torna condição de competitividade. "A diferenciação entre empresas cria variedade tecnológica, o que é uma condição necessária para que haja escolha pelo mercado das mais desejáveis, com sua posterior difusão no tecido econômico, levando à evolução de produtos e de meios de produção e de organização" (COSTA, p.292, 2016).

De acordo Freeman e Perez (1988)4, para além da abordagem inovativa Schumpeteriana, foram introduzidas algumas novas categorias analíticas pelos neoschumpeterianos, uma delas, a abordagem sobre o Sistema Nacional de Inovação (SNI). Já defendido que a empresa tem papel crucial na introdução da inovação na economia, não se pode esquecer, porém que dentro do processo inovativo, a interação entre os diferentes agentes é crucial para a sua potencialização. Edquist $(2006)^{5}$, aponta a inovação como resultado do relacionamento entre a empresa e as demais instituições situadas no campo social, político e financeiro.

Universidades, centros de pesquisa e tecnológicos são colocados como agentes chaves na construção do sistema nacional de inovação, dado que possuem uma base de conhecimento fundamental e formação de capital humano necessários para o desenvolvimento desta, além do governo que, em muitos países, entra como importante apoio ao financiamento do processo produtivo. Conforme Chiarine e Vieira (2012, p.119): "A relação universidade-empresa, em um sistema de inovação, fomenta transbordamentos de conhecimento provenientes da pesquisa e desenvolvimento (P\&D), corporificando-se em novos produtos e/ou novos processos", demostrando que a universidade cumpre importante papel dentro do contexto do SNI.

Etzkowitz e Leydesdorff $(2000)^{6}$, seguindo a abordagem do Modelo de Hélice Tripla (MHT) coloca a universidade como agente capaz de corroborar com a inovação em sociedades onde o conhecimento se faz cada vez mais presente ao atuar de forma conjunta com a indústria e o governo. As relações que se dão entre o setor acadêmico e o produtivo têm se acentuado e, gradualmente, estão sendo favorecidas por políticas públicas de modo que as universidades têm sido apontadas como atores institucionais fundamentais nos sistemas nacionais de inovação (MOWERY e SAMPAT, 2006) ${ }^{7}$. A definição exata de Freeman (1987) para o sistema nacional de inovação é citado por Torres e Botelho (2016) como a rede de instituições nos setores público e privado cujas atividades e interações teriam como objetivo iniciar, importar, modificar e difundir novas tecnologias

[...] a maioria dos neoschumpeterianos, seguindo Lundvall (1992) e seus colegas, enfatiza que um "national system of innovation" é muito mais do que uma rede de instituições de apoio à P\&D; ele envolve redes de relações interfirmas e especialmente elos produtor-usuário de todos os tipos, assim como sistemas de incentivos e apropriabilidade, relações de trabalho e um amplo leque de instituições e políticas governamentais (FREEMAN, 1994 apud COSTA, p. 294, 2016).

Ao se construir um sistema de inovação sólido, com uma interação eficaz entre a empresa e seu processo produtivo com as demais esferas institucionais, principalmente àquelas geradoras de conhecimento e possíveis financiadoras da inovação, se possibilita realizar trocas de informação inerentes ao seu processo de formação e difusão. Assim, conforme Paula (2011), o sistema nacional de inovação se enquadra como uma criação institucional, seja de ações planejadas ou não, que fomenta o progresso tecnológico em economias capitalistas baseadas no conhecimento.

Para a consolidação de um sistema nacional de inovação algumas condições são fundamentais como: i) organizações de ensino e pesquisa produzindo conhecimentos e tecnologias e que mantenham um bom nível de cooperação com as organizações empresariais; ii) um sistema produtivo que introduza sistematicamente inovações de processo e produto a partir da implementação de atividades de P\&D; iii) um conjunto de instituições de prestação de servi-

\footnotetext{
4 Apud Costa (2016)

5 Apud Torres e Botelho (2016)

6 Idem

7 Apud Torres e Botelho (2016)
} 
ços tecnológicos e suporte à infraestrutura tecnológica; iv) um sistema de informações e de indicadores estruturado; v) órgãos reguladores e normas; vi) suporte financeiro; e vii) coordenação tanto por parte do mercado quanto por parte do Estado $(\text { CORDER, 2004) })^{8}$.

O sistema financeiro é, portanto, componente característico do sistema nacional de inovação, pois para o bom desenvolvimento das atividades de P\&D é necessário uma efetiva interação entre as suas diversas formas de financiamento. Além da figura do empresário empreendedor, Schumpeter (1911) ressaltou, o papel do crédito como principal tipo de financiamento para a inovação. De acordo Paula (2011), Schumpeter aponta o crédito como um "complemento monetário da inovação", uma vez que as empresas têm gastos em seu processo inovativo, por exemplo com P\&D, antes de receber qualquer renda como resultado deste processo. Sendo assim, o crédito utilizado principalmente por empresários que não possuem recursos próprios ou fatores de produção que os permitam investir além do habitual, torna-se fundamental para o alcance do objetivo inovador das empresas.

A inovação, principalmente que envolva muita tecnologia, é um processo dispendioso que exige uma grande massa de recursos para poder realizar-se e ainda possui resultados possíveis que são instáveis. Paula (2011), ressalta que investimentos em Pesquisa e Desenvolvimento (P\&D) estão entregues a maior nível de incerteza que os investimentos produtivos, sobretudo em sua fase inicial nos programas de pesquisa, o que dificulta a relação entre financiamento e inovação, uma vez que nesta etapa trata-se ainda de um bem intangível que não se aplica como garantia de crédito para os possíveis financiadores.

Assim, bancos e outros emprestadores, ao preferirem ativos físicos como garantia dos empréstimos, são relutantes em emprestar quando o projeto envolve montantes significativos de investimentos em P\&D. Consequentemente, fluxos de caixa positivos podem ser mais importantes para P\&D do que para investimentos em capital fixo. Contudo, o serviço da dívida normalmente requer uma fonte estável de fluxo de caixa, o que pode não ser o caso dos investimentos em P\&D: dada a natureza dos projetos de inovação, os recursos financeiros para tais projetos são mais difíceis e caros de serem obtidos (PAULA, p.9, 2011).

Deste modo, aqueles que concedem crédito às firmas inovadoras se sentem inibidos de fazê-lo por ser dificultoso analisar de maneira satisfatória o retorno do investimento, dado que, atividades de P\&D geram resultados incertos. Além de poder existir o problema da assimetria de informação entre as partes que envolvem a inovação e ainda, a falta de um ativo tangível que possa ser utilizado como garantia na operação de crédito. Em vista disso, os dispêndios no financiamento da inovação por meio desta modalidade são maiores que nos outros tipos de investimento, resultando no uso dos recursos internos (autofinanciamento), especialmente pelas grandes empresas.

Como dito, um sistema financeiro efetivo é fundamental para a consolidação e aperfeiçoamento do sistema nacional de inovação. Paula (2011), reporta que um sistema financeiro 'praticável' é aquele capacitado para providenciar o financiamento que os empresários precisam para seus gastos com investimento e ainda, a poupança para sustentar as dívidas contraídas tardiamente. Sendo assim, estas condições supracitadas seriam essenciais para que o SNI se desenvolvesse a fim de potencializar a dinâmica inovativa de uma economia. Países com sistema financeiro pouco desenvolvido não conseguem suprir o financiamento das inovações apenas pelo setor bancário através do crédito, como seria o ideal apontado por Schumpeter (1911). Cabe a estas economias, portanto, encontrarem formas alternativas de incentivo ao investimento em atividades de P\&D, além daquelas outras que se enquadram dentro de um processo inovativo.

De acordo com Rapini (2010), há várias formas de financiar a inovação: via aporte do governo (esfera pública), via setor privado ou via interação desses atores. Países com sistema financeiro imaturo somado às incertezas da inovação, apresentam tímida participação do crédito e do sistema bancário para esse financiamento. Sendo assim, a esfera pública passa a ser crucial e pode utilizar de diferentes maneiras para estimular investimento na inovação por meio de: i) projetos de incentivo à atividade de P\&D (empréstimos, incentivos fiscais e recursos não reembolsáveis como bolsas, auxílios, capital de risco e subvenção econômica); ii) programas de compras governamentais; iii) auxílio à infraestrutura de P\&D; e iv) custos de desenvolvimento tecnológico do setor produtivo por parte do governo através de bolsas e/ou recursos não reembolsáveis, encomenda e custeio das atividades necessárias para o desenvolvimento de produtos e processos. Normalmente os recursos que entram na categoria não reembolsável na forma de bolsas ou auxílios, centralizam-se nas universidades e centros de pesquisa a fim de desenvolver projetos em conjunto com o setor produtivo na busca de inovação dos processos e produtos. Já as modalidades capital de risco e subvenção econômica são recursos destinados diretamente para as empresas.

O capital de risco, mais conhecido como venture capital, identifica-se como uma modalidade de investimento onde são aplicados recursos em empresas com maior potencial de crescimento e rentabilidade. Esse tipo de "financiamento" vai além da entrada de recursos na firma, mas também no reparte entre investidor e empreendedor no que tange à aquisição de ações ou ainda na compra de parte da empresa. Geralmente, são utilizados na fase inicial do processo produtivo e servem como grande impulso para pequenas empresas inovadoras com sistemas assentados

8 Apud Torres e Botelho (2016) 
no mercado de capitais. Porém, o venture capital centraliza-se em alguns setores e, além disso, quando abordamos países que não possuem um mercado de capitais consolidado, torna-se uma modalidade de financiamento da inovação limitada e pouco utilizada, restando à esfera pública o encargo de promoção e incentivo do investimento no processo inovativo. O fomento à inovação tecnológica tem se constituído, cada vez mais, numa preocupação dos governos, tanto nos países desenvolvidos como naqueles em desenvolvimento. Dentre as formas mais utilizadas destacam-se os incentivos fiscais (MARCOVITCH et all, 1941, p. 43)

A abordagem da literatura acerca dos incentivos fiscais à P\&D busca compreender e identificar a existência do efeito crowding in, ou efeito adicionalidade, no qual, os incentivos fiscais seriam capazes de estimular as empresas a investirem um montante superior ao que seria investido em P\&D na ausência desse mecanismo. Ou do efeito crowding out, ou efeito substituição, neste segundo, as empresas investiriam em P\&D o mesmo montante independente da utilização do mecanismo fiscal, neste caso os incentivos públicos atuariam como substitutos dos recursos privados (AVELLAR, 2008) ${ }^{10}$. Autores como Zucoloto (2010), Padilha e Ruffoni (2016), Gaspar (2014), Vallim (2014), Avellar (2008), entre outros, são alguns dos que abordaram e analisaram esses efeitos ao estudar os incentivos fiscais como instrumentos de financiamento à inovação no país. No Brasil, esses incentivos podem ser através de subvenções econômicas ou de incentivos tributários e vem sendo destaque dentre as políticas de inovação adotadas.

\section{Abordagem histórica das políticas de inovação no Brasil}

Desde a década de 1930 quando se deu início a industrialização brasileira sob uma agenda de substituição de importações, o país adotou uma política de incentivos fiscais e financeiros. "O Estado protegeu a indústria nascente, apoiou investimentos privados nacionais e estrangeiros, criou e desenvolveu empresas públicas em setores considerados estratégicos para o desenvolvimento nacional” (COSTA, p. 74, 2013).

Apesar da criação de instituições no âmbito federal como o Conselho Nacional de Desenvolvimento Científico e Tecnológico (CNPq) e a Coordenação de Aperfeiçoamento de Pessoal de Nível Superior (CAPES) na década de 1950, da Financiadora de Estudos e Projetos (FINEP) em 1967, do Fundo Nacional de Desenvolvimento Científico e Tecnológico (FNDCT) em 1969, e no âmbito estadual com a criação das FAP's - Fundações de amparo à pesquisa, as políticas adotadas possuíam uma visão linear do processo de inovação, pela qual os investimentos em pesquisa e desenvolvimento, tecnologias e infraestrutura implicariam em avanços que impactariam o setor produtivo repercutindo em inovações.

Na década de 1990, a Política Industrial e de Comércio Exterior (PICE), política industrial vigente, ainda refletia essa perspectiva linear, mas começava a dar passos para uma abordagem mais integrada. Além da liberalização econômica, Vallim (2014) destaca outros objetivos desta política, como sendo: (i) utilizar de maneira eficaz as forças de mercado para promover a modernização tecnológica do parque industrial e o aperfeiçoamento das formas de organização e gestão do trabalho; (ii) reduzir progressivamente os níveis de proteção tarifária; e (iii) fortalecer os mecanismos de defesa da concorrência, entre outros. No período da PICE, com vistas ao desenvolvimento tecnológico, foram criados o Programa Brasileiro de Qualidade e Produtividade (PBQP) e o Programa de Apoio à Capacitação Tecnológica da Indústria (PACTI), visando a melhora da qualidade produtiva, aprendizado tecnológico e a absorção de tecnologias de outros países. Entretanto, o êxito da PICE restringiu-se à liberalização econômica.

Também foi muito relevante a criação dos Fundos Setoriais, a partir de 1999, que atuam como mecanismos de financiamento de projetos de pesquisa, desenvolvimento e inovação no país. As receitas obtidas para os Fundos são provenientes de contribuições incidentes sobre o produto da exploração de recursos naturais pertencentes à União, somado às parcelas do Imposto sobre Produtos Industrializados (IPI) de certos setores e de Contribuições de Intervenção no Domínio Econômico (CIDE) incidentes sobre os valores que remuneram o uso ou aquisição de conhecimentos tecnológicos/transferência de tecnologia do exterior. Os recursos dos fundos são angariados de setores específicos e são usados para financiar aquele determinado setor não podendo ser desviados para outros seguimentos ou ações (FINEP, 2017).

Ainda na década de 1990 foram criadas as Leis nº 8.248/91 voltada para o setor de informática e automação; e nº 8.661/93 que estabeleceu os planos de desenvolvimento tecnológico da agropecuária (PDTA) e da indústria (PDTI) ${ }^{11}$. Tais planos eram constituídos de incentivos fiscais às empresas que fizessem investimento em P\&D e em capacitação tecnológica visando promover uma melhoria do potencial produtivo da indústria e da agropecuária. Referente a última Lei citada, de acordo com Matesco e Tafner $(1996)^{12}$, fora criada com intuito de deslocar para as empresas

9 Apud PADILHA e RUFONNI (2016)

10 Apud ZUCOLOTO (2010)

11 Esses incentivos se referiam ao abatimento do imposto de renda (IR) e do imposto sobre produtos industrializados (IPI), crédito de imposto de renda, redução de impostos sobre operações financeiras (IOF) e dedução de despesas com pagamento de royalties e com assistência técnica (JUNIOR e PORTO, 2012).

12 Apud Junior e Porto (2012). 
parte do papel na geração e difusão do desenvolvimento tecnológico. Os autores ainda destacam que mais tarde, o pouco conhecimento por parte das empresas em relação a essa Lei, as dificuldades e entraves burocráticos para acessá-la, bem como seu caráter inconsistente em razão do incentivo ser dependente da apuração da lucratividade da firma, desestimularam as empresas de acessá-la. Essa inadequação da Lei às expectativas dos investidores foi indutora da criação de novas regulamentações.

A partir da década de 2000, conforme apontam os estudos de Vallim (2014), Negri e Moraes (2016), as políticas começam a ter uma visão mais sistêmica e integrada do processo de inovação. Em 2004, foi lançada a Política de Inovação Tecnológica e de Comércio Exterior (PITCE), que visava promover um ambiente de inovação através de várias vertentes, no âmbito legal por meio de leis como a Lei da Informática (no 11.077 de 2004) e a Lei do Bem (n⿳ 11.196 de 2005). No que tange ao crédito, promoveria a concessão por meio dos Fundos Setoriais geridos pela FINEP, linhas específicas de crédito do BNDES, bem como diversas outras fontes, além da implementação de políticas públicas de inovação e consolidação das instituições de P\&D e daquelas que fomentavam a inovação no país. Calzolaio e Dathein (2011), destacam a importância deste período pelo enfoque dado à necessidade de uma política de inovação consistente:

A Política Industrial, Tecnológica e de Comércio Exterior (PITCE), implementada em 2004, no início do primeiro governo Lula, foi base para a formulação de uma nova matriz jurídica voltada à promoção da produção residente. Nesse contexto surgiu o novo modelo de incentivo fiscal à inovação no Brasil, contido na Lei n ${ }^{\circ} 11.196 / 05$, conhecida como Lei do Bem por trazer uma série de apoios que resultam em redução de impostos à produção industrial, cujo objetivo é o desenvolvimento econômico (CALZOLAIO e DATHEIN, p.6, 2011).

Neste contexto sistêmico das políticas de inovação, os incentivos fiscais tiveram novamente destaque. A Lei no 11.077 de 2004, apresentou grande representatividade neste período, sendo a versão mais recente da conhecida Lei da Informática da década de 1990 (Lei n 8.248/91) visava, em substituição da reserva de mercado até então existente, incentivar a produção na área de automação e informática no país. Para tanto, eram oferecidos incentivos fiscais em contrapartida a investimentos de no mínimo 5\% do faturamento em P\&D nessas áreas, dos quais no mínimo 2\% deveriam ocorrer em parcerias com universidades e institutos de pesquisa. Albuquerque e Bonacelli (2009), ressaltam que a Lei dava prioridade aos convênios com centros, institutos de pesquisa ou entidades brasileiras de ensino, oficiais ou reconhecidas ${ }^{13}$, com sede ou estabelecimento principal nas regiões de influência das Superintendências de Desenvolvimento da Amazônia (Sudam), do Nordeste (Sudene) e outras regiões delimitadas pela Lei. Em 2001, os percentuais destinados às parcerias, bem como outras regulamentações, foram alterados pela Lei n⿳0 10.176/01.

As empresas do setor de informática e automação que investissem em P\&D na área de TIC deixariam de ter isenção plena do IPI, embora continuassem a se beneficiar desse dispositivo. Como os demais benefícios foram mantidos, conclui-se que o espirito da lei anterior foi mantido, ou seja, baseia-se na concessão de estímulos fiscais mediante ao atendimento de obrigações relativas à realização de investimentos em P\&D [...]. Outro aspecto importante introduzido na lei de 2001 foi o seu enfoque no desenvolvimento regional. Desta forma, empresas que investissem nas Regiões Norte, Nordeste e Centro-Oeste do país passariam a se beneficiar de incentivos diferenciados (ALBUQUERQUE e BONACELLI, p. 205, 2009).

Posteriormente, a Lei 11.077 de 2004 também deu continuidade às alterações na Lei da Informática, entretanto os incentivos continuaram e os benefícios oriundos da Lei anterior passariam a vigorar até 2019, havendo um escalonamento para redução das isenções. "A Lei de Informática possui características distintas dos incentivos fiscais tradicionais ao investimento em P\&D\&I, já que a Lei é orientada a um setor e dependente de aprovação de projeto” (JUNIOR e PORTO, p. 3, 2012). Em contraste à Lei da informática que teve sua abrangência restrita a setores específicos, a Lei do Bem (n⿳0 11.196 de 2005) alcança a todos os setores da economia. A Lei do Bem surge como uma consequência da Lei da Inovação (n⿳⺈ 10.973/04) que determina a responsabilidade da União no fomento das atividades de inovação pelas empresas por meio de incentivos fiscais. Até então, esses incentivos eram abarcados pela Lei no 8.661/93 que instituiu o PDTA e o PDTI. A Lei do Bem surge abarcando e revogando as Leis 8.661/93 e 10.637/02, que ampliava os incentivos da anterior.

Conforme Zucoloto (2010), a Lei do Bem, com sua criação simplifica os procedimentos burocráticos por não exigir aprovação de projetos ou participação em editais de licitações para acesso aos incentivos, sendo que o uso da Lei é opcional à empresa. Contudo, para ter acesso aos benefícios, esta deve ser tributada pelo regime de 'lucro real', precisa estar em dia com suas obrigações fiscais e preencher um documento chamado 'Formulário para Informações sobre as Atividades de Pesquisa Tecnológica e Desenvolvimento de Inovação Tecnológica' (FORMP\&D) e, posteriormente, encaminhá-lo ao Ministério da Ciência, Tecnologia e Inovação e Comunicações (MCTIC, 2013) ${ }^{14}$.

13 Entidades credenciadas pelo Comitê Gestor da Área de Tecnologia da Informação (CATI) (ALBUQUERQUE e BONACELLI, 2009).

14 Apud Padilha e Ruffoni (2016) 
O que se observa é que o esforço brasileiro no sentido de viabilizar melhores condições em CT\&I se amparou em Políticas Públicas que foram avançando na medida em que o tempo foi passando. Foram criados novos artefatos que visavam promover a atividade inovativa. Uma das formas como essa promoção acontece é através dos incentivos fiscais às empresas que inovam, onde se enquadra a Lei do Bem (PADILHA e RUFFONI, 2016).

\section{Quadro 1 -Programas de incentivo à inovação adotados no Brasil (2003- 2014)}

\begin{tabular}{|c|c|}
\hline Programas de apoio a inovação & Modalidades de apoio financeiro \\
\hline Pró-inovação (2003) & Custeio e investimento para inovação: médias e grandes empresas \\
\hline Lei no $10.973 / 2004$ & $\begin{array}{l}\text { Medidas de incentivo à inovação e à pesquisa científica e } \\
\text { tecnológica no ambiente produtivo (Incentivo Fiscal). }\end{array}$ \\
\hline Lei no 11.196/05 (Lei do Bem) & Incentivo fiscal voltado para inovação. \\
\hline Juro Zero (2006) & $\begin{array}{c}\text { Investimentos para inovação: micro e pequenas empresas. Juros } \\
\text { Zero, mas com correção do IPCA sem o capital }\end{array}$ \\
\hline Subvenção a empresas (2006) & Subvenção para custeio de inovações. Recursos a fundo perdido \\
\hline Pappe Subvenção (2006) & $\begin{array}{c}\text { Subvenção para custeio de inovações de MPEs, via instituições } \\
\text { estaduais e locais }\end{array}$ \\
\hline $\begin{array}{l}\text { Finep/Sebrae/ICTs } \\
\text { (Chamadas públicas) }\end{array}$ & $\begin{array}{c}\text { Apoio não reembolsável para inovação a empresas localizadas em } \\
\text { APLs }\end{array}$ \\
\hline Inova Brasil (2008) & Custeio e investimento para inovação: médias e grandes empresas \\
\hline Prime - primeira empresa inovadora (2009) & $\begin{array}{l}\text { Subvenção a empresa nascente para contratação de recursos } \\
\text { humanos e estudos de mercado, serviços jurídicos e financeiros }\end{array}$ \\
\hline $\begin{array}{l}\text { Inova Empresa (Aerodefesa, Agronegócio, } \\
\text { Energia, Petro, Saúde, Sustentabilidade, Telecom, } \\
\text { Paiss, Paiss Agrícola) }\end{array}$ & $\begin{array}{l}\text { Integração: crédito (BNDES), subvenção, recursos não reembolsáveis } \\
\text { e fundos de venture capital (Plano de Suporte Conjunto) }\end{array}$ \\
\hline Tecnova (Subvenção) & $\begin{array}{l}\text { Descentralização da subvenção econômica para MPEs (custeio): } 21 \\
\text { fundações de amparo à pesquisa }\end{array}$ \\
\hline $\begin{array}{l}\text { Inovacred Empresa e ICT (inovação para a } \\
\text { competitividade) }\end{array}$ & $\begin{array}{c}\text { Descentralização do crédito para MPEs:14 bancos de fomento } \\
\text { estaduais. }\end{array}$ \\
\hline Inovacred Expresso & $\begin{array}{c}\text { Financiamento para inovações a empresas e ICTs com Receita } \\
\text { Operacional Bruta de } 3 \text { de até R } \$ 16 \text { milhões }\end{array}$ \\
\hline Inovacred Parceiros & $\begin{array}{c}\text { Financiamento para inovações a empresas e ICTs com Receita } \\
\text { Operacional Bruta de até R } \$ 90 \text { milhões }\end{array}$ \\
\hline Financiamento reembolsável & Crédito a médias e grandes empresas (ROB3 acima de $\mathrm{R} \$ 16$ milhões) \\
\hline $\begin{array}{l}\text { Financiamento não reembolsável cooperação } \\
\text { ICTs-empresa }\end{array}$ & $\begin{array}{l}\text { Instituições científicas e tecnológicas nacionais em parcerias com } \\
\text { empresas }\end{array}$ \\
\hline
\end{tabular}

Em seu capítulo III, a Lei do Bem estabelece os benefícios fiscais aos quais as empresas investidoras em P\&D podem usufruir de maneira automática caso atendam os requisitos legais. Os benefícios concedidos pela Lei são: i) deduções de IR e da CSLL ${ }^{15}$ de dispêndios efetuados em atividades de P\&D; ii) redução de 50\% do IPI na compra de máquinas e 15 Contribuição Social Sobre Lucro Líquido (CSLL) 
equipamentos para P\&D; iii) depreciação e amortização acelerada de equipamentos e bens intangíveis para P\&D; iv) isenção do IR retido na fonte nas remessas efetuadas para o exterior destinadas ao registro e manutenção de marcas, patentes e cultivares; e v) subvenções econômicas, incorporadas à linha de financiamento FINEP Inova Brasil, concedidas em virtude de contratações de pesquisadores, titulados como mestres ou doutores, empregados em empresas para realizar atividades de pesquisa, desenvolvimento e inovação tecnológica.

As atividades que estão sujeitas à incorporação dos benefícios estabelecidos pela Lei do Bem são: i) aquisição de máquinas, equipamentos, instrumentos e acessórios destinados a P\&D; ii) aquisição de bens intangíveis vinculados a P\&D de inovação tecnológica; iii) registros e manutenção de marcas e patentes; iv) construção de espaços físicos para P\&D; v) pesquisa em P\&D para inovação; vi) contratação de pesquisadores; vii) aquisição de royalties, assistência técnica ou científica e serviços especializados, cooperação entre empresas e universidades, centro de pesquisas, micro/ pequenas empresas (MPE's) e inventores independentes; e viii) construção de espaços físicos destinados a laboratórios de P\&D dentro das empresas (CALZOLAIO e DATHEIN, 2011).

Após a implementação da Lei do Bem, em 2005, continuaram as iniciativas governamentais para incentivo a inovação. Negri e Morais (2016), fizeram um estudo sobre a evolução das ações e programas da FINEP que visaram estímulo à inovação empresarial no período entre 2003 e 2014. Os autores trazem um quadro que resume esses programas:

Pós-2003, a FINEP passou a dispor de recursos e regulamentações legais que possibilitaram lançar diversos programas de incentivo à inovação pelo setor produtivo em várias modalidades como: subvenções econômicas, concessões de créditos com taxas de juros subsidiadas e programas de participação acionária em fundos empresariais por meio de venture capital. Neste período, os Fundos Setoriais possibilitaram à financiadora realizar empréstimos às empresas com taxas de juros reduzidas, compatibilizadas com os riscos das atividades inovativas. A parceria com as FAP's também oportunizou avanços como a realização da pré-seleção de MPEs candidatas a financiamentos e subvenções proporcionando diversos resultados positivos (NEGRI e MORAIS, 2016). Segundo esses autores, a atuação em parceria com as FAP's proporcionou:

i) maior capilaridade na concessão de recursos das fontes institucionais utilizadas (Fundo de Amparo ao Trabalhador - FAT e Fundo Verde Amarelo - FVA); ii) divisão dos riscos dos financiamentos entre a FINEP e os estados, por meio da formação de fundo estadual de garantia de crédito; e iii) diminuição das assimetrias de informações entre a FINEP e as empresas candidatas a apoio financeiro, em razão do conhecimento e do contato mais estreito da instituição estadual com as empresas locais selecionadas (NEGRI e MORAIS, p. 21, 2016).

O financiamento à inovação continuava um entrave para os avanços neste campo. Os Fundos Setoriais ainda não se mostravam capazes de suprir tal demanda. No período de 2011 a 2014, os planos criados buscavam aumentar a participação do setor produtivo nesse financiamento, ampliando a capilaridade dos programas de incentivo à inovação. Os novos programas objetivavam, juntamente com o aperfeiçoamento de programas que já apresentavam resultados positivos: integrar instrumentos e mecanismos de estímulo à inovação; incentivar as empresas a investirem mais em P\&D de projetos de maior risco; incitar uma maior articulação entre o setor produtivo e as universidades/ ICTs; melhorar a condição dos serviços prestados às empresas e às ICT's; diminuir a pulverização que ocorria em alguns dos programas de apoio às empresas; e maximizar os volumes de recursos a serem disponibilizados às empresas (JUNIOR e PORTO, 2012).

Em 2013, é lançado o Plano Inova como componente das medidas de política do governo federal voltadas à melhoria da produtividade e competitividade das empresas nacionais e instaladas no país, através da inovação tecnológica (CORDER, BUAINAIN e JUNIOR, 2016). O Plano buscava colocar a empresa como o principal agente dos projetos de inovação financiados pelo BNDES e FINEP, esse protagonismo atribuído às empresas se daria através de editais para concessões de crédito, subvenção econômica e recursos não reembolsáveis para projetos em parceria entre ICTs e as empresas, bem como, por meio de chamadas públicas para a seleção dos projetos.

O Plano Inova foi pautado em seis pilares: i) Elevação de P\&D nas empresas; ii) incentivo a projetos de maior risco tecnológico; iii) integração dos instrumentos de financiamento; iv) intensificação do uso do poder de compra do estado; v) descentralização do crédito e da subvenção econômica; e vi) redução de prazos e simplificação administrativa. O Plano contava com estimativas de um orçamento volumoso que seria operacionalizado pelo governo em parceria com entidades como o SEBRAE, Agências Reguladoras, Ministérios e etc, tendo como orientação as prioridades setoriais e estratégicas definidas no Plano Brasil Maior ${ }^{16}$, que era a política industrial determinada para vigorar a partir de 2012 (CORDER, BUAINAIN e JUNIOR, 2016).

Após implantação do Plano Inova o cenário econômico e político do país tem passado por um período conturbado com cortes e contingenciamentos de gastos implementados pelo governo. O que fez com que um percentual aquém do esperado fosse investido e o Plano Inova, por sua pouca maturação, não fosse implementado como planejado.

16 O Plano Brasil Maior, foi implementado objetivando dar continuidade e aprofundar medidas relacionadas às políticas industriais adotadas anteriormente - PITCE (2003-2007) e PDP (2008-2010). 
Diante desse cenário econômico, torna-se relevante avaliar os resultados das políticas de inovação sob alguns indicadores, visando mensurar se estas foram exitosas ou não em relação ao estímulo à inovação. Neste sentido, o presente trabalho pretende identificar através das PINTEC's 2008, 2011 e 2014, de dados secundários do MCTIC e de resultados de estudos correlatos, se os benefícios oriundos dos incentivos fiscais, mais especificamente, através da Lei da Informática e da Lei do Bem contribuíram para o estímulo e incremento ao investimento em inovação pelo setor industrial.

\section{O desempenho das políticas de incentivos fiscais como indutores da atividade industrial brasileira}

Nesta seção, busca-se observar o desempenho dos incentivos fiscais como mecanismo indutor da atividade inovativa no setor industrial brasileiro. Para tanto, foram utilizados dois instrumentos: i) estudos correlatos e suas principais contribuições sobre o tema; ii) relatório e dados secundários das PINTECs de 2008, 2011 e 2014.

A Pesquisa de Inovação Tecnológica (PINTEC) é executada pelo Instituo Brasileiro de Geografia e Estatística (IBGE), tem por objetivo fornecer informações para a construção de indicadores das atividades de inovação das empresas brasileiras e todas suas edições encontram-se disponíveis no site de sua instituição de origem. Sua publicação é trienal, ou seja, a última publicação de 2014 cobriu todo o triênio de 2012 - 2014. Para o presente estudo foram observados os dados dos relatórios das PINTECs de 2008, 2011 e 2014, deste modo, a periodicidade utilizada data do ano de 2006 até 2014.

No que tange a pesquisa bibliográfica (estudos correlatos), o conteúdo sobre a contribuição dos incentivos fiscais no incremento a inovação no país é recorrente na literatura: Salles Filho et al (2012), avaliaram os impactos da Lei da Informática no que tange à inovação no setor de TIC's brasileiro; Junior e Porto (2012), analisaram as políticas recentes de incentivos fiscais à inovação; Vallim (2014), pesquisou a evolução dos principais instrumentos de financiamento à inovação no Brasil no período 2003-2012. Padilha e Ruffoni (2016), analisaram a Lei do Bem visando verificar a influência ou não do programa na capacidade inovativa da empresa, utilizando um grupo de empresas do Rio Grande do Sul (RS) enquanto Pereira (2013), Zucoloto (2010), Gaspar (2014), Calzolaio e Dathein (2011), Negri e Moraes (2016), entre outros autores analisaram a Lei do Bem como mecanismo de incentivo à inovação.

Conforme Pereira (2013), a Lei da Inovação, tendo como principais instrumentos a Lei da Informática e a Lei do Bem, só conseguirá repercutir em resultados concretos se as indústrias realmente tiverem a necessidade de inovar, ou seja, o processo de inovação não ocorre pela oferta desses mecanismos, mas sim decorre da necessidade de competição por novos mercados, que exigem maior sofisticação. Logo, esses instrumentos precisam ir além de uma abertura de novas possibilidades e buscar uma garantia de que as agências de governo incentivem adequadamente o uso dos instrumentos disponíveis (PEREIRA, 2013).

$\mathrm{Na}$ tabela 1, observa-se a evolução ou involução ocorrida ao longo do período 2006-2014, do acesso pelas empresas do setor industrial aos diversos programas do governo para estímulo à inovação. No geral, entre 2012-2014, $40,0 \%$ das empresas inovadoras receberam algum apoio do governo para suas atividades inovativas, proporção maior que a observada no período 2009-2011, onde o percentual foi de 34,2\%. Entretanto, a participação em cada um dos programas apresentou comportamentos díspares.

Em relação a Lei do Bem, percebe-se um aumento do número de empresas beneficiadas ao longo do período, a quantidade de empresas participantes mais que dobrou de 2006 a 2014, passando de 440 (2006-2008) para 1.367 (2012-2014). Entretanto, a representatividade sobre o total de empresas ainda é pequena, das 42.988 empresas beneficiadas por algum programa de apoio do governo no triênio 2012-2014, apenas 1.367 fizeram uso da Lei do Bem, ou seja, 3,17\% do total. Contudo, segundo dados do Relatório da PINTEC 2014, se for tomado como universo apenas as empresas cujo o porte abrange 500 ou mais pessoas ocupadas, $37,7 \%$ destas empresas de grande porte são beneficiadas pela Lei do Bem, corroborando o que alguns estudos ressaltam sobre a concentração desses benefícios entre as empresas de maior porte, o que corresponde aos parâmetros que precisam ser atendidos para usufruto da Lei.

Ressaltam-se ainda os volumes de recursos investidos através da renúncia fiscal em contraste com uma concentração na distribuição desses recursos, no que tange ao número de empresas beneficiadas. Sobre os impactos da Lei nos investimentos em P\&D, o Ministério de Ciência Tecnologia e Inovação e Comunicações (MCTIC) traz dados atualizados até 2014, sobre os investimentos em P\&D e a renúncia fiscal das empresas participantes da Lei do Bem (Gráfico 1). Percebe-se uma equivalência no comportamento de ambos, apresentando crescimento entre 2006 e 2008. Porém, a partir deste último até 2009 inicia-se um declínio, o que pode ser consequência da crise financeira em 2008. Entre 2009 e 2010, registrou-se recuperação do crescimento, uma brusca queda após 2010 e posterior recuperação após 2012. Na visão exposta pelo Relatório Anual dos Incentivos Fiscais/MCTIC, os resultados demonstram que o setor industrial brasileiro continua crédulo no investimento em P\&D como propulsor de uma competitividade frente ao mercado internacional e no conhecimento tecnológico como diferencial competitivo. 
Tabela 1: Empresas do setor industrial que implementaram inovação e receberam apoio do governo para suas atividades inovativas, por programa de apoio. Brasil (2006 a 2014)

\begin{tabular}{|c|c|c|c|c|c|c|c|c|c|}
\hline \multirow{5}{*}{$\begin{array}{l}\text { Perí } \\
\text { odo }\end{array}$} & \multicolumn{9}{|c|}{ Empresas do setor industrial que implementaram inovações } \\
\hline & \multirow{4}{*}{ Total } & \multicolumn{8}{|c|}{ Receberam apoio do governo (por programa) } \\
\hline & & \multicolumn{2}{|c|}{ Incentivo Fiscal } & \multirow{3}{*}{$\begin{array}{l}\text { Sub. } \\
\text { Econô } \\
\text { mica }\end{array}$} & \multicolumn{3}{|c|}{ Financiamento } & \multirow{3}{*}{$\begin{array}{l}\text { Compras } \\
\text { públicas }\end{array}$} & \multirow{3}{*}{$\begin{array}{l}\text { Outros } \\
\text { progra- } \\
\text { mas de } \\
\text { apoio1 }\end{array}$} \\
\hline & & \multirow[b]{2}{*}{$\begin{array}{c}\text { À P\&D } \\
\text { (Lei do } \\
\text { Bem) }\end{array}$} & \multirow[b]{2}{*}{$\begin{array}{l}\text { Lei } \\
\text { Infor } \\
\text { mática }\end{array}$} & & \multicolumn{2}{|c|}{ À projetos de $\mathrm{P} \& \mathrm{D}$} & \multirow{2}{*}{$\begin{array}{l}\text { Compra } \\
\text { de } \\
\text { máquina } \\
\text { equipa } \\
\text { mento }\end{array}$} & & \\
\hline & & & & & $\begin{array}{c}\text { Sem } \\
\text { parceria } \\
\text { com } \\
\text { universidade } \\
\end{array}$ & $\begin{array}{c}\text { Em } \\
\text { parceria } \\
\text { com } \\
\text { universidade }\end{array}$ & & & \\
\hline $\begin{array}{l}2006- \\
2008\end{array}$ & 38299 & 440 & 704 & 207 & 528 & 323 & 5457 & - & 2728 \\
\hline $\begin{array}{l}2009- \\
2011\end{array}$ & 41470 & 1044 & 618 & 314 & 502 & 389 & 11345 & - & 3143 \\
\hline $\begin{array}{l}2012- \\
2014\end{array}$ & 42988 & 1367 & 457 & 233 & 659 & 376 & 13490 & 604 & 3435 \\
\hline
\end{tabular}

Fonte: IBGE - PINTEC 2008, 2011, 2014, elaboração própria

Nota 1: Outros programas de apoio referem-se aos incentivos fiscais concedidos pelos estados, especificamente para o desenvolvimento de P\&D; recursos aplicados em P\&D provenientes do Fundo Setorial de Energia Elétrica e demais categorias não contempladas nas anteriores.

Figura 1 - Lei do Bem: Renúncia Fiscal e Investimentos em P\&D no Brasil (em bilhões de R\$) - 2006 a 2014

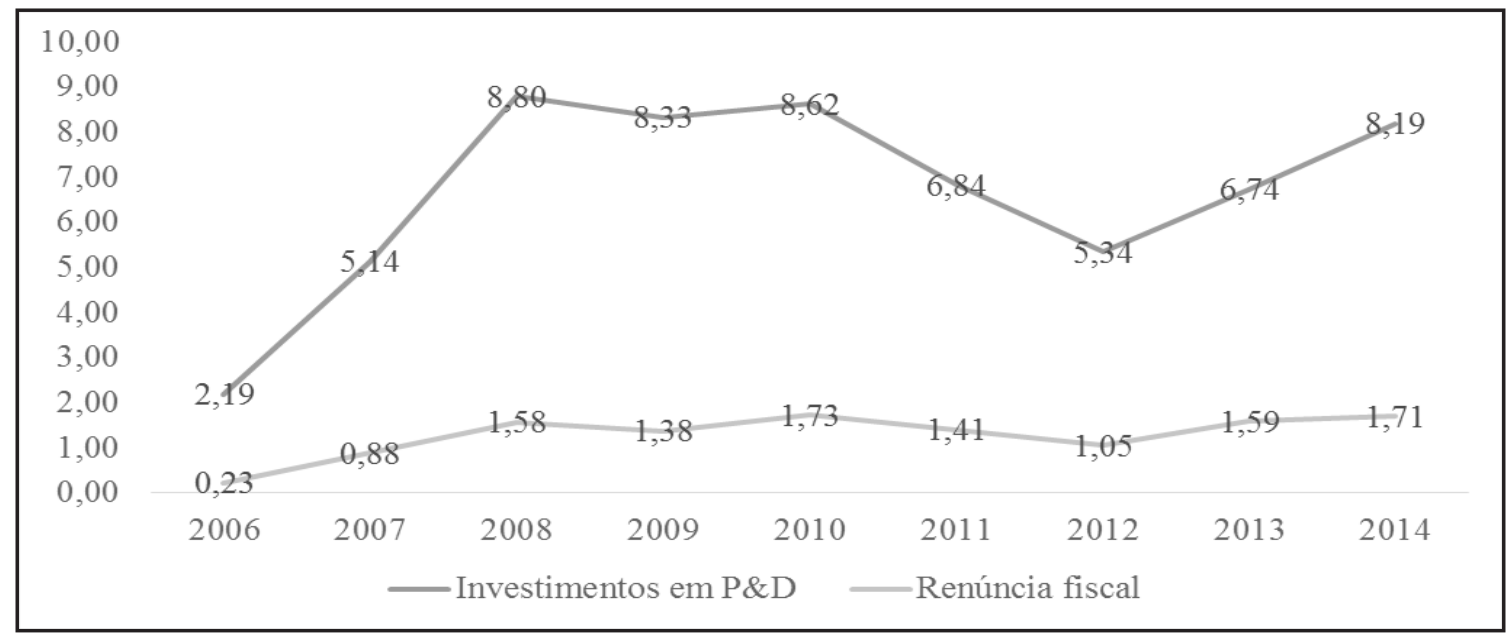

Fonte: Relatório Anual de Incentivos Fiscais - Lei do Bem/MCTIC/SETEC, 2014

Prosseguindo a abordagem sobre os impactos da Lei do Bem na atividade inovativa industrial, faz-se um resgate de estudos análogos que demonstraram um contraste a análise supracitada na avaliação da referida Lei. Calzolaio e Dathein (2011), concluíram que o incentivo fiscal à inovação é um instrumento adequado para intensificar no curto prazo as atividades de inovação que já estão sendo executadas. Entretanto, não expande significativamente a base de empresas inovadoras, além de não ser adequado para apoio de projetos arriscados, com elevado aporte de capital e comprometimento de custos de longo prazo. Junior e Porto (2012), através de modelos econométricos, estimam que o impacto da Lei do Bem sobre o nível de dispêndios em P\&D\&I interno pelas empresas seja, em média, de 7\% a $11 \%$. Porém, segundo os autores, tal percentual não gerou efetividade no incentivo às atividades de P\&D nas empresas, uma vez que tal incentivo não foi capaz de torná-las produtoras de bens de competitividade internacional. 
Zucoloto (2010), em seu estudo sobre os impactos da Lei do Bem nas atividades de P\&D no Brasil, faz uma crítica a capacidade do mecanismo de promover uma maior diversificação setorial destes investimentos, uma vez que o acesso aos benefícios é majoritariamente conseguido por setores que já investiam em P\&D. Padilha e Ruffoni (2016), chegaram a resultados análogos:

[..] havendo ou não a Lei do Bem, as firmas permaneceriam na busca pela inovação; que inovar é fundamental para manter e obter vantagem competitiva e que os investimentos nesta atividade são definidos mais pela dinâmica de mercado do que pela existência de incentivos públicos. Assim, os benefícios são considerados como algo adicional, mas não a base para a inovação, demonstrando que o incentivo legal não revelou-se um fator determinante para a realização da inovação pelas firmas investigadas (PADILHA e RUFFONI, 2016).

No caso da Lei da Informática, percebe-se na análise das PINTEC’s 2008, 2011 e 2014 (Tabela 1) uma queda no número de empresas beneficiadas no setor industrial, de 704 no período 2006-2008 para 457 no período 2012-2014. Pode-se inferir que as alterações ocorridas na legislação veem reduzindo progressivamente os percentuais de isenção praticáveis ou, até mesmo, que esta redução seja fruto da introdução da Lei do Bem a partir de 2004, que por abarcar todos os setores, possibilitar acesso automático e desburocratizado aos benefícios, pode estar sendo utilizada por empresas da indústria de TIC's.

Apesar dos dados da PINTEC 2014 relatarem uma queda no número de empresas do setor industrial que foram beneficiadas, dados levantados até 2014 pelo Sistema de Gestão da Política de Informática (SIGPLANI) do MCTIC revelam que o número de empresas no geral (todos os setores) continua a crescer anualmente, passando de $437 \mathrm{em}$ 2011 para 510 em 2014. Todavia, ainda é um número irrisório se contrastado com os valores referentes à renúncia fiscal decorrente deste instrumento (Gráfico 2). Entre o período 2006-2014, a renúncia fiscal por parte do governo com relação às empresas beneficiárias da Lei da Informática alcança 40,0\% daquilo que seria o total do potencial de arrecadação (impostos pagos). Esse aspecto tem atribuído críticas ao instrumento no que tange à avaliação desta política pública e seu retorno para o posicionamento do país no cenário internacional.

Figura 2 - Impostos Pagos e Renúncia Fiscal referentes a bens incentivados no Brasil (em milhões de R\$), 2006 a 2014

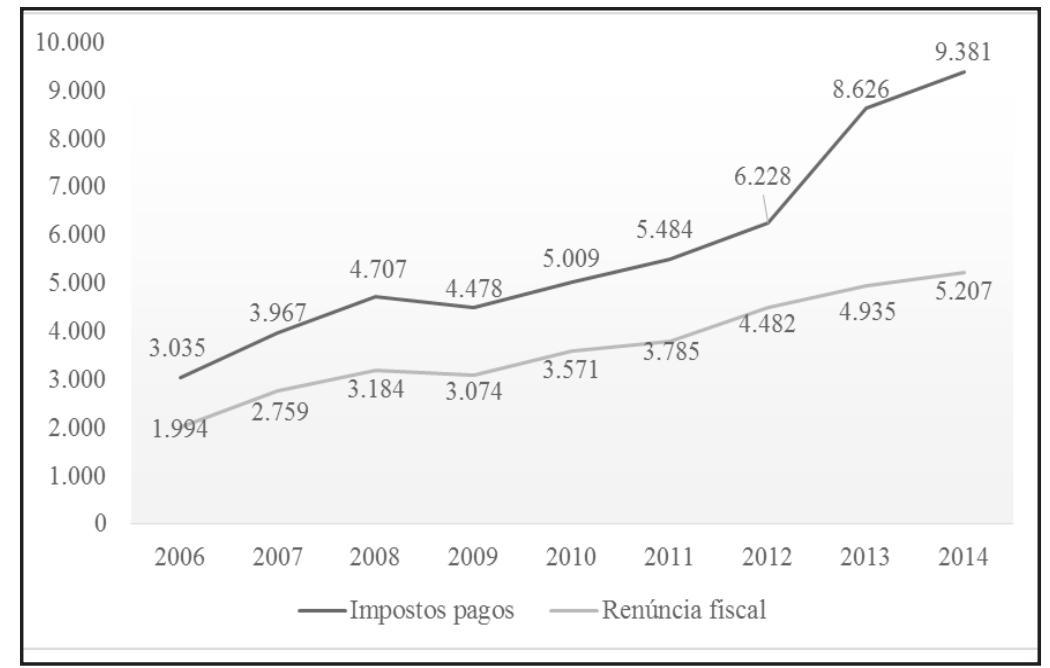

Fonte: SIGPLANI, Ministério da Ciência, Tecnologia e Inovação, 2014

Avançando da análise dos dados secundários para os resultados de estudos correlatos, consegue-se observar uma consistência entre os resultados dos trabalhos com os dados do SIGPLANI/MCTIC. Conforme Salles Filho et al. (2012), através da Lei da Informática houve um adensamento da cadeia produtiva de TIC's no Brasil, dado que o benefício permitiu e impulsionou as empresas beneficiadas investirem em atividades de P\&D três vezes mais do que a média da indústria brasileira de TICs investiu em P\&D desde a sua criação. Porém, apesar do aumento de investimento nesta atividade por parte das TICs, não se observa um aumento de investimento na densidade tecnológica no setor.

Salles Filho et al. (2012), ainda ressaltam que os benefícios da Lei possibilitam a redução de custos e competitividade por preço, quadriplicando o faturamento das beneficiárias. Porém, os incentivos da Lei de Informática não têm sido capazes de guiar o país em direção a uma participação mais significativa no mercado global como exportador. Sobre esse posicionamento os dados da SIGPLANI/MCTIC presentes no Gráfico 3 corroboram esse comportamento errático entre investimentos em inovação e os retornos de faturamento das empresas com os bens incentivados pelo mecanismo fiscal. Os dados demonstram um comportamento ascendente no faturamento dessas 
empresas, lembrando que, conforme relatório do Ministério, os valores de faturamento são referentes apenas aos bens incentivados. Esse crescimento no faturamento acompanha a mesma tendência de crescimento da renúncia fiscal (Gráfico 2). Contudo, os valores investidos têm oscilações bem menores, demonstrando um comportamento estacionário e, em alguns períodos, até mesmo de queda, conforme se pode observar nos anos de 2011 e 2014 em relação aos anos que os antecedem. Resultado diferente do encontrado para a Lei do Bem, onde os dados do Ministério demonstram um comportamento similar entre a renúncia fiscal e os valores investidos em P\&D (Gráfico 1).

Figura 3 - Investimento em inovação e Faturamento Bruto Total das Empresas Habilitadas referentes aos bens incentivados no Brasil (em R\$ milhões) - 2006 a 2014

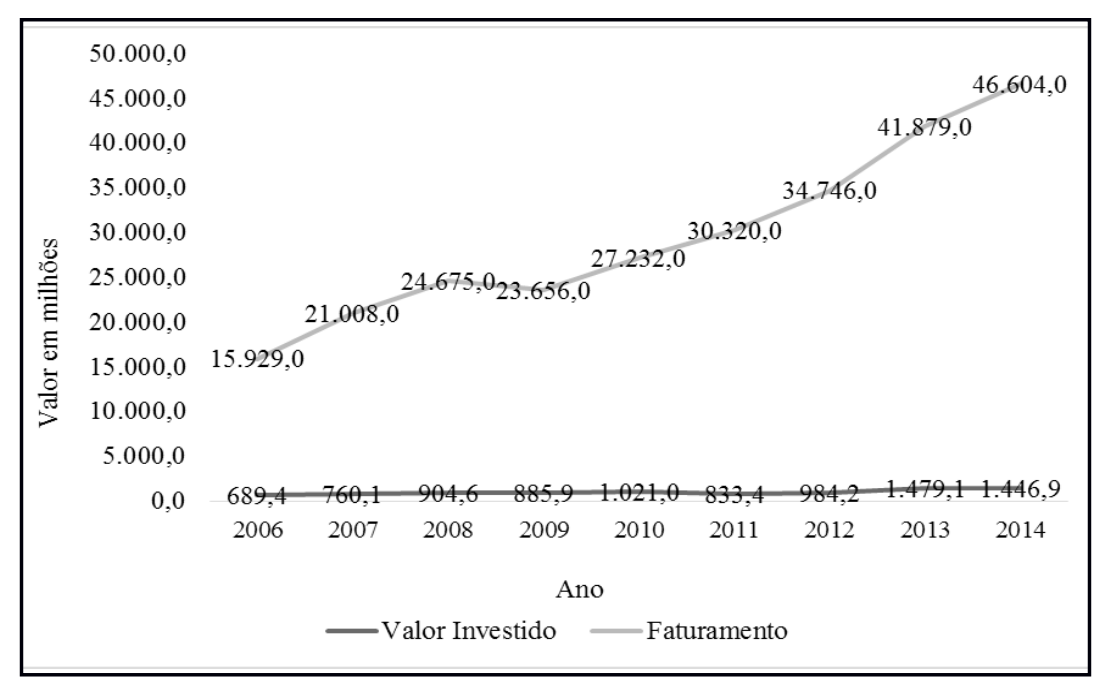

Fonte: SIGPLANI, Ministério da Ciência, Tecnologia e Inovação, 2014

Vallim (2014), analisou a Lei da Informática no período 2006-2013 e também concluiu que houve aumento da capacidade inovativa das empresas, porém sem avanços na densidade tecnológica do setor. O estudo também destacou os resultados de uma pesquisa sobre a Lei, realizada pelo Centro de Gestão de Estudos Estratégicos (CGEE) em 2011, segundo os resultados a maioria das empresas beneficiárias apontaram a renúncia fiscal como o principal motivador para uso da Lei, ficando à frente do número de empresas que apontaram o aumento da competitividade como aspecto motivador. Em relação ao incremento aos investimentos em inovação, a pesquisa concluiu, conforme Junior e Porto (2012), que o aumento do faturamento das empresas beneficiadas não foi compatível com o aumento dos investimentos em P\&D, apesar das empresas incentivadas investirem mais do que as não incentivadas, o anacronismo da lei aliando incentivos fiscais com exigências de conteúdo de nacionalização dos produtos, estratégias de política regional e um viés discricionário na aprovação de projetos a torna ineficiente no sentido de promoção de um efeito crowding in nas empresas beneficiárias.

Vallim (2014), também destaca a pouca efetividade da Lei no que tange às parcerias com as ICT's. Em seu estudo ele aponta, com base em dados do CGEE, que o investimento, em parceria com essas instituições estabelecida pela Lei da Informática, ficou concentrado em um número reduzido de instituições. De um total de 263 ICT's, aptas a auferir investimentos, no período de 1998 a 2008, por exemplo, apenas 92 delas chegaram a acessar algum tipo de convênio com as empresas beneficiárias. Dentre elas, apenas 20 embolsaram $84 \%$ dos valores alocados pelas empresas. A concentração regional também foi apontada na pesquisa. A região sudeste concentrou $52 \%$ dos recursos, em contraste, somando as regiões nordeste e centro-oeste o total foi de $40 \%$. O baixo nível de integração entre as ICT's e as empresas beneficiárias também foi apontada nas PINTEC's: em 2008 a participação de empresas inovadoras no setor industrial que utilizaram os financiamentos de projetos de P\&D e inovação tecnológica em parceria com ICT's alcançou apenas $0,8 \%$ do total de empresas; e entre 2011 e 2014 , permaneceu praticamente estagnado em $0,9 \%$ (PINTEC, 2008).

\section{Autofinanciamento}

Como já abordado, há diversas maneiras de se financiar o processo inovativo das empresas. O crédito contempla a modalidade mais indicada e bem aceita pela teoria econômica, principalmente por Schumpeter, que o aponta como o complemento monetário da inovação. Porém, em economias onde o sistema financeiro ainda não 
está consolidado -limitando o mercado de capitais - e, o sistema bancário vê-se inibido para dar suporte financeiro às atividades inovativas, dado os grandes riscos (sobretudo na fase inicial do processo), os incentivos advindos do governo tornam-se variável fundamental de estímulo ao investimento nas atividades ligadas à inovação.

Todavia, apesar de ter-se observado na discussão realizada ao longo desse artigo que aumentou o número de empresas inovadoras do setor industrial que utilizam dos incentivos fiscais e de outros instrumentos de apoio do governo para o financiamento de seu processo inovativo, é verificado na Tabela 2 que o uso de recursos próprios, por parte das empresas brasileiras, vem sendo a principal fonte de financiamento da inovação. Corder (2004), reforça tal situação ao ressaltar a baixa participação do sistema bancário privado e do mercado de capitais doméstico como fomentadores das atividades de P\&D\&I realizadas no país, cabendo as empresas brasileiras utilizar seus recursos internos advindos da retenção de lucros para o financiamento de tais atividades.

Em seus estudos, Freeman e Soete $(2008)^{17}$ apontam que mesmo em situações onde o nível de risco dos investimentos em inovação seja baixo, há uma proporção pequena do processo inovativo financiada pelo mercado de capitais ou ainda por aporte do governo, sendo predominante os recursos financeiros internos próprios da empresa, ou seja, os lucros retidos. Deste modo, o autofinanciamento torna-se importante pauta na discussão sobre o financiamento das inovações, sendo uma temática rica a ser explorada em trabalhos futuros.

Tabela 2 - Fontes de financiamento das atividades internas de Pesquisa e Desenvolvimento e das demais atividades inovativas realizadas pelas empresas no setor da indústria no Brasil - 2006 a 2014.

\begin{tabular}{|c|c|c|c|c|c|c|c|c|}
\hline \multirow{4}{*}{ Período } & \multicolumn{8}{|c|}{ Estrutura de financiamento } \\
\hline & \multicolumn{4}{|c|}{ Atividades de P\&D (interno) } & \multicolumn{4}{|c|}{ Demais atividades inovadoras } \\
\hline & \multirow{2}{*}{ Próprias } & \multicolumn{3}{|c|}{ Terceiros } & \multirow{2}{*}{ Próprias } & \multicolumn{3}{|c|}{ Terceiros } \\
\hline & & Privado & Público & Total & & Privado & Público & Total \\
\hline $2006-2008$ & 76,0 & 5,0 & 19,0 & 24,0 & 75,0 & 9,0 & 16,0 & 25,0 \\
\hline $2009-2011$ & 87,0 & 2,0 & 11,0 & 13,0 & 78,0 & 5,0 & 17,0 & 22,0 \\
\hline $2012-2014$ & 84,0 & 1,0 & 15,0 & 16,0 & 85,0 & 3,0 & 12,0 & 15,0 \\
\hline
\end{tabular}

Fonte: IBGE, PINTEC 2008, 2011 e 2014, elaboração própria

Com relação às atividades de P\&D internas às empresas inovativas brasileiras, de acordo a Tabela 2 , no período de 2006 a 2008, 76,0\% foram financiadas por recursos próprios e os $24 \%$ restantes foram financiados por terceiros, sendo $19 \%$ de recursos públicos ligados à concessão de crédito pelo Banco Nacional de Desenvolvimento (BNDES). No período de 2012 a 2014, essa proporção aumentou, sendo 84,0\% dos recursos gastos nesta atividade inovativa específica, financiados pelas próprias empresas.

No que tange às demais atividades inovativas, como P\&D externo, por exemplo, também vigora o autofinanciamento como a principal fonte de recursos, no período mais recente (2012-2014), 85,0\% desta fase do processo inovativo receberam este tipo de financiamento. Em todos os anos, a participação do setor privado foi reduzida, diminuindo ao passar dos anos. Para as demais atividades inovadoras, portanto, entre 2012 e $2014,97,0 \%$ destas atividades foram financiadas por recursos próprios da empresa e do setor público, com foco no crédito concedido pelo BNDES.

\section{Considerações Finais}

A inovação, como aponta Schumpeter, é fundamental no processo de desenvolvimento econômico, uma vez que é uma variável intrínseca ao sistema capitalista causadora de suas instabilidades ao provocar rupturas tecnológicas, ocorrendo então a transformação dos mercados e dos sistemas produtivos. As novas combinações introduzidas pelas empresas são, portanto, decisórias nas mudanças econômicas existentes. Para potencializar a inovação, muitos países veem-se impelidos a consolidar um sistema nacional de inovação, em que ocorre interação da empresa com demais esferas institucionais, com o intuito de fomentar o progresso tecnológico em economias capitalistas baseadas no conhecimento.

17 Apud Torres e Botelho (2016) 
Para alcance de tal desígnio, faz-se necessário, como aponta Paula (2011), um sistema financeiro bem amparado, uma vez que este é um apêndice do sistema nacional de inovação. Como já apontava Schumpeter, o crédito se torna crucial fonte de financiamento para a inovação, sendo o meio que o empresário aufere recursos para adiantar os pagamentos inerentes ao processo inovativo. Todavia, economias que não contam com um sistema financeiro eficiente e sólido, precisam buscar alternativas de financiamento da inovação, visto que o sistema bancário muitas vezes se vê inibido de conceder crédito às empresas inovadoras por se tratar de um empreendimento de grande risco, de difícil mensuração dos possíveis retornos, além de não possuir uma garantia tangível na operação de crédito. Não obtendo, portanto, um grande aporte do setor privado, cabe ao Estado, através dos mais diversos mecanismos, promover o impulso e o financiamento indireto do processo inovativo através de projetos de incentivo à atividade de P\&D (empréstimos, incentivos fiscais e recursos não reembolsáveis como bolsas, auxílios, capital de risco e subvenção econômica); programas de compras governamentais; auxílio à infraestrutura de P\&D; entre outros, sendo que os incentivos fiscais se constituem a principal política de inovação adotada por países com as características financeiras supracitadas.

Dado que o Brasil se enquadra no perfil dos países com um sistema financeiro deficitário, a presença do governo nas políticas de inovação para promover o financiamento e o impulso desta atividade no país é condição essencial. O presente artigo objetivou, portanto, abordar sob a perspectiva do financiamento da inovação, a influência dos incentivos fiscais na atividade inovativa industrial brasileira, com ênfase nas Leis da Informática e Lei do Bem. A partir da análise de estudos correlatos sobre o desempenho das políticas de incentivos fiscais como indutores da atividade inovativa, depreende-se que estes são considerados importantes ferramentas para que o Estado promova o investimento pelo setor produtivo e apoie as empresas nessas atividades, tornando mais atrativos os investimentos frente à característica de incerteza inerente às atividades de inovação. Porém, identificou-se nos estudos aqui abordados uma recorrência do chamado efeito crowding out, em detrimento do efeito crowding in, ou seja, os autores aqui apontados inferem que as políticas de incentivos fiscais não têm sido significativas para o incremento de investimentos à inovação. Isto implica que os recursos públicos têm sido utilizados como substitutos dos recursos privados no que tange ao financiamento das inovações, uma vez que as empresas investiriam em P\&D o mesmo montante independente da utilização do mecanismo fiscal.

Os questionamentos sobre a efetividade dos incentivos fiscais, como indutores de investimentos em inovação no setor industrial, compreendem vários outros aspectos: a concentração em empresas de maior porte; a concentração em determinados setores da indústria (como apontam pesquisas e até mesmo os dados das PINTEC's); a capacidade de apoio desses incentivos para investimentos de longo prazo e com elevado aporte de capital; o volume expressivo de recursos públicos investidos, demonstrados pelos números da renúncia fiscal em contraste a outras áreas carentes de investimentos; e o potencial de retorno desses investimentos. Esses questionamentos aliados aos resultados que demonstram os benefícios destes incentivos para a inovação e aumento da competividade do país indicam a necessidade de adaptações na legislação para promoção da diversificação setorial, acesso às empresas de menor porte (ainda que os benefícios fiscais sejam diferentes, compatíveis com sua estrutura fiscal), bem como regulamentações para o aumento dos investimentos e parcerias com as ICT's que ainda se demonstra incipiente, implicando a fragilidade das relações no SNI brasileiro.

Ademais, é importante ressaltar que, apesar de todo esforço advindo das políticas de inovação implementadas nos últimos anos, percebe-se a baixa aderência destes programas de apoio do governo por parte das empresas industriais inovadoras, sendo que no período de 2012 - 2014, de acordo com Relatório da PINTEC 2014, apenas 40\% das empresas que estão inseridas em atividades inovativas, utilizaram algum tipo destes programas. E ainda, de todas as empresas que fazem parte deste montante, apenas 3,2\% utilizaram dos benefícios da Lei do Bem e 1,1\% da Lei da Informática. Em contrapartida, neste mesmo período, de acordo com os dados disponíveis na PINTEC 2014, $84,0 \%$ das empresas utilizaram de recursos próprios (lucros retidos) para financiar as atividades internas de P\&D, enquanto que $85,0 \%$ autofinanciaram suas demais atividades inovadoras, inclusive P\&D externo.

Deste modo, infere-se que os incentivos fiscais constituem-se importante variável da política de inovação brasileira em conjunto com outros programas de apoio oferecidos pelo governo. Porém, questiona-se sua eficácia visto que as empresas têm recorrido pouco ao aporte do governo para financiarem sua inovação, sendo o autofinanciamento a modalidade mais utilizada e, bem aceita, pelas empresas industriais inovadoras brasileiras.

\section{Referências}

ALBUQUeRQUe, M.; E. E; BONACELli, M. B. M. Contribuições dos institutos de pesquisa privados sem fins lucrativos do setor de TICs ao desenvolvimento da C\&T no Brasil: uma análise a partir do uso dos incentivos da Lei de Informática. Parcerias Estratégicas, Brasília-DF, v. 14, n. 28, p. 195-218, jan-jun 2009. 
AVEllaR, A. P. M; OliVeiRA, F. C. B. Comportamento do sistema Nacional de Inovação Brasileiro (2000-2007). Revista Economia Ensaios, v. 23, n. 8. UFU. Uberlândia. 2008.

BRASIL. FINEP - Financiadora de estudos e projetos. Rio de Janeiro: FINEP, 2017. Disponível em: http://www. finep.gov.br

BRASIL. FINEP. Instituto Brasileiro de Geografia e Estatística - IBGE. Pesquisa industrial de inovação tecnológica: análise dos resultados. Rio de Janeiro: IBGE, 2008.

BRASIL. FINEP. Instituto Brasileiro de Geografia e Estatística - IBGE. Pesquisa industrial de inovação tecnológica: análise dos resultados. Rio de Janeiro: IBGE, 2011.

BRASIL. FINEP. Instituto Brasileiro de Geografia e Estatística - IBGE. Pesquisa industrial de inovação tecnológica: análise dos resultados. Rio de Janeiro: IBGE, 2014.

BRASIL. FINEP. Ministério da Ciência e Tecnologia. Relatório anual da utilização dos incentivos fiscais - Ano Base 2014, Brasil, 2014. Disponível em: www.mctic.gov.br.

BRASIL. FINEP. Pesquisa de Inovação Tecnológica (PINTEC-2014). Disponível em: http://www.pintec.ibge.gov. br. Acesso em: setembro de 2017.

CAlzOlAiO, A.; DATHEIN, R. Políticas fiscais de incentivo à inovação: uma avaliação da lei do Bem. 2011.

CGEE. Avaliação de impactos da Lei de Informática no Brasil - 1998 a 2008. Brasil: UNICAMP, 2011.

CHIARINI, T; VIEIRA, K. P. Universidades como produtoras de conhecimento para o desenvolvimento econômico: sistema superior de ensino e as políticas de CT\&I. Revista Brasileira de Economia. Rio de Janeiro, v. 66, n.1, p. 117-132, jan-mar 2012.

CORDER, S.; BUAINAIN, A. M.; JUNIOR, I.de S. L. Análise preliminar do Plano Inova Empresa, p.156-173. In: Anais do 1ํㅡㄹ Encontro Nacional de Economia Industrial e Inovação. São Paulo: Blucher, 2016.

COSTA, A. C. Política de inovação brasileira: análise dos novos instrumentos operados pela finep. 247 f. Tese (Doutor em Economia) - Universidade Federal do Rio de Janeiro, Rio de Janeiro, 2013.

COSTA, A. B. da. Teoria econômica e política de inovação. Revista de Economia Contemporânea. Rio de Janeiro, v. 20, n.2, p. 281-307, mai-ago 2016.

GASPAR, B. F. Impacto da Lei do Bem e do Plano Inova na capacidade inovativa da firma. 1ํㅡㄹ edição, Brasília-DF, UNB: 2014.

KANNEBLEY JUNIOR, S.; PORTO G. Incentivos Fiscais à Pesquisa, Desenvolvimento e Inovação no Brasil: Uma avaliação das políticas recentes. Documento para Discussão № 236, Banco Interamericano de Desenvolvimento-IDB, Brasília - DF, Setembro de 2012.

NEGRI, J. A. de. MORAIS, J. M. de. Evolução das ações e programas da finep no apoio à inovação empresarial 2003-2014. Radar-IPEA, Brasília-DF, n. 48, p. 19-24, dez 2016.

PADILHA, F.; RUFFONI, J. De que forma a Lei do bem incentiva a atividade inovativa das firmas? Uma reflexão para empresas selecionadas no Rio Grande do Sul. In: $1^{\circ}$ Encontro Nacional de Economia Industrial e Inovação, UNESP, 2016.

PAULA, L. F. R. Sistema Financeiro e o Financiamento da Inovação: Uma abordagem keynesianaschumpeteriana. In: $\mathbf{3 9}^{\circ}$ Encontro Nacional de Economia ANPEC, 2011.

PAVITT, K. What makes basic research economically useful? Elsevier Science Publishers B.V. North-Holland, 1990. 
PEREIRA, J. M. Uma avaliação das políticas públicas de incentivo a inovação tecnológica no Brasil: a Lei do Bem. Parcerias Estratégicas: Edição Especial, Brasília-DF, v. 18, n. 36, p. 221-250, jan-jun 2013.

RAPINI, M. S. O Financiamento aos investimentos em inovação no Brasil. 2010. 146 f. Tese (Doutorado em Economia) - Instituo de Economia, Universidade Federal do Rio de Janeiro, Rio de Janeiro. 2010.

SALLES FILHO, S S., et al. Avaliação de impactos da Lei de Informática: uma análise da política industrial e de incentivo à inovação no setor de TICs brasileiro. Revista Brasileira de Inovação, Campinas-SP, v.11, n. especial, p. 191-218, julho 2012 .

SCHUMPETER, J. A Teoria do Desenvolvimento Econômico. São Paulo: Nova Cultural, 1985.

SILVA, L. N. F. Incentivos Fiscais ao esforço inovativo e à inovação no Brasil: uma análise crítica da gestão governamental. 2018. 136 f. Dissertação (Mestrado em Economia) - Universidade Estadual Paulista "Júlio de Mesquita Filho”, Araraquara, 2018.

TORRES, R. L. A “inovação” na teoria econômica: uma revisão. VI Encontro de Economia Catarinense; 26 e 27 de Abril de 2012; Joinville-SC, 2012.

TORRES, P.H; BOTELHO, M. dos R. A. Financiamento a inovação e interação entre atividades científicas e tecnológicas: uma análise a partir do PAPPE. XVII Seminário sobre a Economia Mineira; 29 de Agosto a 02 de Setembro de 2016, Diamantina-MG, 2016.

VALLIM, R. B. O Financiamento à inovação nas empresas no contexto do Sistema Nacional de Inovação brasileiro. 2014. 170 f. Dissertação (Mestrado em Economia) - Universidade Federal do Rio de Janeiro, Rio de Janeiro, 2014.

ZUCOLOTO, G. F. Lei do Bem: impactos nas atividades de P\&D no Brasil. Radar-IPEA, Brasília-DF, n. 06, p. 14-20, fev 2010. 